\title{
Effect of Resident Staffing for Acute Stroke Rehabilitation in the Neurosurgery Unit
}

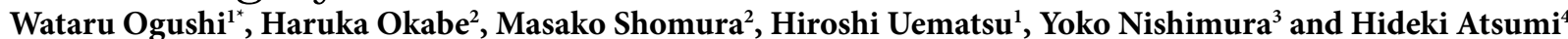

${ }^{1}$ Department of Nursing, Tokai University Hospital, 143 Shimokasuya, Isehara-shi, Kanagawa 259-1193, Japan

${ }^{2}$ Faculty of Nursing, School of Medicine, Tokai University, 143 Shimokasuya, Isehara-shi, Kanagawa 259-1193, Japan

${ }^{3}$ Department of Rehabilitation Services, Tokai University Hospital, 143 Shimokasuya, Isehara-shi, Kanagawa 259-1193, Japan

${ }^{4}$ Department of Neurosurgery, Tokai University School of Medicine, 143 Shimokasuya, Isehara-shi, Kanagawa 259-1193, Japan

\begin{abstract}
Background: This study aimed to investigate if a difference existed in inpatient recovery with the placement of resident rehabilitation staff in the general neurosurgery ward and an increase in cooperation between rehabilitation staff and nurses and to determine the effectiveness of resident rehabilitation staff placement for nurses and patients.
\end{abstract}

Methods: A retrospective observational study design was adopted using data from existing medical records. Data of 301 patients in the neurosurgery unit were statistically and retrospectively analyzed using the t-test, $\chi 2$ test, and multiple regression analysis.

Results: Analyses revealed that resident staffing for acute stroke rehabilitation might contribute to shorter hospitalization, increased cooperation records on nursing and rehabilitation, increased home discharge, and improved activities of daily living (ADL), bowel and bladder control.

Conclusion: Resident staffing for acute stroke rehabilitation might strengthen the cooperation between nurses and rehabilitation staff and improve the patients' ADL, hospitalization, and quality of life.

\section{Introduction}

Over 13.7 million new strokes occur each year around the world [1]. Globally, one in four people over the age of 25 are likely to have a stroke in their lifetime [2]. In Japan, the number of patients with new stroke is estimated at 290,000 per year [3]. In recent years, due to the increasing aged population and soaring medical expenses, it has been difficult to establish a medical system closely related to community-based facilities, which involves shortening the length of hospitalizations, strengthening early rehabilitation, and increasing home discharge from acute care hospitals. In addition, the 2014 revised medical fees indicated the placement of rehabilitation professionals in the advanced and acute phases, thereby promoting rehabilitation from an early stage of hospitalization.

In Europe and the United States, skilled nursing care and specialist rehabilitation are core aspects of a comprehensive stroke unit, and treatment in such facilities has been shown to reduce mortality and disability [4]. The establishment of multidisciplinary stroke wards has also been recommended by the stroke societies of Europe and the United States [5,6] and in a Cochrane Review [7] to improve patient outcomes. Large-scale clinical studies have also revealed that treatment in super-acute stroke wards reduces deaths and hospitalizations [8]. In contrast, in Japan, the establishment of multidisciplinary stroke specialist wards is trailing that of Europe and the United States. Moreover, several facilities manage patients with stroke together with patients in the general ward, intensive care unit, and high care unit via related medical departments and multidisciplinary experts' collaborative efforts. Therefore, the effect of designating staff exclusively to stroke rehabilitation on the outcomes of patients in the general ward remains unclear in Japan.

Since December 2014, the Department of Rehabilitation Services at the [blinded information] (Japan) has been piloting the stationing of rehabilitation staff at the Advanced Critical Care and Emergency
Center, neurosurgery ward, and neurology ward, and conducting early rehabilitation from the acute phase. Recently, in A Very Early Rehabilitation Trial for acute stroke, the placement of full-time physiotherapists facilitated easier cooperation between doctors and nurses in situations where the condition of acute patients changed significantly; the greatest advantage of this is that early rehabilitation can be performed frequently, thereby improving the prognosis of patients with stroke [9]. Moreover, the placement of a dedicated rehabilitation therapist in the ward increased the patients' training time, shortened the hospitalization of patients, and accelerated activities of daily living (ADL) acquisition by cooperation with nurses [10]. Resident rehabilitation staff has been assigned to the neurosurgery and neurology wards of our hospital, which makes it easier to collaborate with the Department of Rehabilitation Services. Thus, we have been providing interventions from the viewpoint of rehabilitation. However, it has not yet been clarified how the placement of resident rehabilitation staff in the general ward affects the early rehabilitation of patients and strengthens the collaboration between nurses and the rehabilitation staff. Therefore, it is necessary to clarify the effect of the placement of resident rehabilitation staff on the medical personnel and patients. In this study, "pre-resident rehabilitation staffing" is defined as the absence of resident rehabilitation staff in the general neurosurgery unit; therefore, the therapists visited the neurosurgery ward from the general rehabilitation center only when the physicians required an intervention for patients with stroke. In contrast, "post-

"Corresponding Author: Wataru Ogushi, Department of Nursing, Toka University Hospital,143 Shimokasuya, Isehara-shi, Kanagawa 259-1193, Japan, Tel: 0463-93-1121; Fax: 0463-90-2035, E-mail: o.wataru.92@gmail.com

Citation: Ogushi W, Okabe H, Shomura M, Uematsu H, Nishimura Y, et al. (2021) Effect of Resident Staffing for Acute Stroke Rehabilitation in the Neurosurgery Unit. Int J Nurs Clin Pract 8: 348. doi: https://doi.org/10.15344/2394-4978/2021/348

Copyright: (c) 2021 Ogushi et al. This is an open-access article distributed under the terms of the Creative Commons Attribution License, which permits unrestricted use, distribution, and reproduction in any medium, provided the original author and source are credited. 
resident rehabilitation staffing" is defined as the presence of more than one occupational therapist in the neurosurgery ward from 9 am to $5 \mathrm{pm}$. Resident rehabilitation staffing is expected to increase the number of rehabilitation interventions for patients with stroke and improve the team approach, such as better communication among the team members, timely sharing of information about the patients' ADL status, and better accessibility to the therapists. Finally, it might improve the clinical outcomes of patients with stroke, including shortening the duration of hospitalization, improving ADLs, and increasing home discharge rates.

This study aimed to investigate whether there was a difference in patient recovery with the placement of resident rehabilitation staff in the general neurosurgery ward and an increase in cooperation between all rehabilitation staff and nurses. Additionally, we aimed to determine the effectiveness of the placement of resident rehabilitation staff for nurses and patients. Therefore, our study may contribute to the evidence for the effectiveness of resident rehabilitation staffing in acute stroke rehabilitation and help in making it mandatory in all acute stroke units in Japan.

\section{Materials and Methods}

The investigation conformed with the principles outlined in the Declaration of Helsinki (2000) of the World Medical Association. Ethical approval was obtained from the Institutional Review Board of [blinded information], Japan ([blinded information]). We adopted a retrospective observational study design using the data from existing medical records. The patients were informed regarding the use of their medical data in this study through informational posters.

The eligible patients were classified into two groups as follows: group 1, with pre-resident staffing for acute stroke rehabilitation from December 1, 2013, to November 30, 2014, and group 2, with post-resident staffing for acute stroke rehabilitation from December 1,2014 , to November 30,2015. The patients in both groups were aged $\geq 20$ years and were transported to our hospital in an ambulance, admitted to the Advanced Critical Care Center, and transferred or discharged from our neurosurgery ward. The patients were diagnosed with cerebral hemorrhage, subarachnoid hemorrhage, or cerebral infarction. We excluded patients who died during hospitalization.

In our center, a neurosurgeon or a neurologist asks a rehabilitation doctor to start rehabilitation, and eventually, the rehabilitation doctor instructs a related medical physician and staff to start rehabilitation. The criteria for starting rehabilitation include sufficient stability of the patient's general condition for the neurosurgeons or neurologists and agreement of the rehabilitation physicians to initiate rehabilitation by observing stable vital signs and verifying that physical examination results are normal.

\section{Outcomes}

The primary endpoint was the duration of hospitalization. The secondary endpoints included 1) Barthel Index (BI) scores at the time of admission and discharge, 2) diet at the time of discharge, 3) several days required to resume oral intake, 4) several days required to start rehabilitation, and 5) number of nursing and rehabilitation records in collaboration between the patients' nurses and the Department of Rehabilitation Services. The number of nursing and rehabilitation records in this study was defined as the number of records of instances of collaboration between nurses and rehabilitation staff. That is, one record is written for each instance of collaboration.

The specific observation items extracted from the medical records were age, sex, major diagnosis, responsible lesion site, medical history (hypertension, diabetes mellitus, hyperlipidemia, intracerebral hemorrhage, subcutaneous hemorrhage, and cerebral infarction), and the level of consciousness at the time of admission and discharge, determined by coma scales such as the Japan Coma Scale (JCS) and Glasgow Coma Scale. In addition, the ward nurses evaluated the BI scores routinely, as well as family care situations, at the time of admission and discharge. In patients with stroke, the subscale of the BI score is also correlated with scores, such as the Functional Independence Measure, and it has been clarified that the subordinate items of the BI score accurately reflect the patient's daily behavior and functional situation [11].

\section{Statistical Analysis}

The purpose variables were the characteristics and clinical findings of the patients and pre-and post-resident staff placement for rehabilitation, such as age, major diagnosis, and patient status at the time of discharge. In addition, the cooperation between all rehabilitation staff and nurses (i.e., the numbers of the rehabilitation and nursing records) was compared using the $t$-test and $\chi 2$ test. We used Kaplan-Meier analysis to determine the differences in hospitalization days, staffing, and major diagnoses. Factors related to the hospitalization period and home discharge were analyzed using logistic regression analysis, and $\mathrm{p}$ values $<0.05$ were considered statistically significant.

\section{Results}

Research participants comprised the 301 patients in the neurosurgery unit. The numbers of patients in groups 1 and 2 were 165 and 136, respectively. There were no significant differences in age, sex, and major diagnosis between the two groups. However, the duration of hospitalization was significantly shorter post-staffing than pre-staffing. In addition, the number of nursing and rehabilitation records per day, home discharge rates, and BI scores of bowel and bladder control significantly increased post-staffing (Table 1).

The factors associated with home discharge were determined using logistic analysis (Table 2). In the univariate analysis, older age, longer hospitalization, number of days required to start rehabilitation and resume oral intake, and worsened JCS scores had a negative effect on home discharge. In contrast, better BI scores were positively associated with home discharge. In the multivariate analysis, we chose 10 variables as independent factors, such as resident rehabilitation staffing, age, family care, JCS score at discharge, BI scores of feeding, transfer, bladder control, the number of days required to start rehabilitation, and the number of nursing and rehabilitation cooperation records. We observed that resident staffing for acute stroke rehabilitation and better BI scores of feeding and transfer positively contributed to home discharge. In contrast, worsened JCS scores at discharge had a negative effect on home discharge. Hence, we noted four factors independently associated with home discharge.

The factors associated with hospitalization, determined by logistic regression analysis, are shown in Table 3 . In the univariate analysis, the number of days required to start rehabilitation and resume oral intake, worsened JCS score at discharge, and worsened diet 
Citation: Ogushi W, Okabe H, Shomura M, Uematsu H, Nishimura Y, et al. (2021) Effect of Resident Staffing for Acute Stroke Rehabilitation in the Neurosurgery Unit. Int J Nurs Clin Pract 8: 348. doi: https://doi.org/10.15344/2394-4978/2021/348

Page 3 of 5

\begin{tabular}{|c|c|c|c|}
\hline Variables & Pre-staffing group $(\mathrm{n}=166)$ & Post-staffing group $(\mathrm{n}=136)$ & P-value \\
\hline Sex: Male/Female & $84(50.6) / 82(49.4)$ & $66(48.5) / 70(51.5)$ & 0.68 \\
\hline $\begin{array}{l}\text { Major diagnosis: } \\
\text { SAH/cerebral hemorrhage/cerebral } \\
\text { infarction }\end{array}$ & $59(36) / 85(51) / 22(13)$ & $49(36) / 66(49) / 21(15)$ & 0.83 \\
\hline Age (years) & $66.0 \pm 14.3$ & $66.5 \pm 13.8$ & 0.73 \\
\hline Medical history: Hypertension +/- & $102(61) / 64(39)$ & $78(57) / 58(43)$ & 0.47 \\
\hline Hospitalization (days) & $51.4 \pm 35.2$ & $42.2 \pm 28.8$ & 0.01 \\
\hline $\begin{array}{l}\text { Number of days required to start } \\
\text { rehabilitation }\end{array}$ & $5.7 \pm 3.6$ & $5.4 \pm 3.3$ & 0.71 \\
\hline $\begin{array}{l}\text { Number of days required to start } \\
\text { oral intake }\end{array}$ & $21 \pm 18(\mathrm{n}=69)$ & $17 \pm 19(\mathrm{n}=55)$ & 0.56 \\
\hline Number of nursing records per day & $0.2 \pm 0.6$ & $0.5 \pm 1.0$ & 0.00 \\
\hline $\begin{array}{l}\text { Number of rehabilitation records } \\
\text { per day }\end{array}$ & $0.2 \pm 0.7$ & $0.6 \pm 1.2$ & 0.00 \\
\hline $\begin{array}{l}\text { Japan Coma Scale score } \\
0 / 1 / 2 / 3 / 10 / 20 / 30 / 100 / 200\end{array}$ & $\begin{array}{l}65(43) / 23(15) / 21(14) / 26(17) / 5(3) / 6 \\
(4) / 4(3) / 0(0) / 1(1)\end{array}$ & $\begin{array}{l}66(51) / 20(15) / 7(5) / 22(17) / 7(5) / 4(3) / 3 \\
(2) / 1(1) / 0(0)\end{array}$ & 0.35 \\
\hline $\begin{array}{l}\text { Turning point: home discharge/ } \\
\text { others }\end{array}$ & $40(24) / 125(76)$ & $48(35) / 88(65)$ & 0.04 \\
\hline \multicolumn{4}{|l|}{ Dietary form at the time of discharge: } \\
\hline $\begin{array}{l}\text { NPO or TF/jelly-like food or less/ } \\
\text { start meal or more }\end{array}$ & $36(22) / 26(16) / 103(62)$ & $24(18) / 21(15) / 91(67)$ & 0.64 \\
\hline \multicolumn{4}{|c|}{ Barthel Index scores at the time of admission } \\
\hline Feeding: 0/5/10 & $111(67) / 38(23) / 17(10)$ & $98(72) / 37(27) / 1(1)$ & 0.009 \\
\hline Mobility on level surfaces: $0 / 5 / 10 / 15$ & $122(73) / 27(16) / 17(10) / 0(0)$ & $105(77) / 30(22) / 1(1) / 0(0)$ & 0.002 \\
\hline Bowel control: $0 / 5 / 10$ & $110(66) / 42(25) / 14(8)$ & $95(70) / 38(28) / 3(2)$ & 0.096 \\
\hline Bladder control: 0/5/10 & $111(67) / 40(24) / 15(9)$ & $94(69) / 40(29) / 2(2)$ & 0.021 \\
\hline Toilet use: $0 / 5 / 10$ & $120(72) / 33(20) / 13(\%)$ & $102(75) / 33(24) / 1(1)$ & 0.024 \\
\hline Dressing: 0/5/10 & $122(73) / 36(22) / 8(5)$ & $97(71) / 38(28) / 1(1)$ & 0.14 \\
\hline Stairs: $0 / 5 / 10$ & $122(73) / 28(17) / 16(10)$ & $108(79) / 27(20) / 1(1)$ & 0.008 \\
\hline $\begin{array}{l}\text { Transfers (bed to chair and back): } \\
0 / 5 / 10 / 15\end{array}$ & $118(71) / 23(14) / 13(8) / 12(7)$ & $100(73) / 19(14) / 15(11) / 2(2)$ & 0.019 \\
\hline Grooming: 0/5 & $154(93) / 12(7)$ & $135(99) / 1(1)$ & 0.014 \\
\hline Bathing: $0 / 5$ & $148(89) / 18(11)$ & $135(99) / 1(1)$ & 0.001 \\
\hline \multicolumn{4}{|c|}{ Barthel Index scores at the time of discharge } \\
\hline Feeding: 0/5/10 & $53(32) / 31(19) / 81(49)$ & $47(35) / 16(12) / 73(54)$ & 0.25 \\
\hline Mobility on level surfaces: $0 / 5 / 10 / 15$ & $70(43) / 10(6) / 21(13) / 62(38)$ & $55(40) / 9(7) / 14(10) / 58(43)$ & 0.81 \\
\hline Bowel control: 0/5/10 & $67(41) / 22(13) / 76(46)$ & $52(38) / 6(4) / 78(58)$ & 0.02 \\
\hline Bladder control: 0/5/10 & $67(41) / 22(13) / 76(46)$ & $52(38) / 5(4) / 79(58)$ & 0.01 \\
\hline Toilet use: $0 / 5 / 10$ & $71(43) / 31(19) / 63(38)$ & $55(40) / 21(15) / 60(44)$ & 0.54 \\
\hline Dressing: 0/5/10 & $71(43) / 32(20) / 61(37)$ & $55(40) / 17(13) / 64(47)$ & 0.13 \\
\hline Stairs: 0/5/10 & $78(48) / 25(16) / 58(36)$ & $62(46) / 14(10) / 59(44)$ & 0.26 \\
\hline $\begin{array}{l}\text { Transfers (bed to chair and back): } \\
0 / 5 / 10 / 15\end{array}$ & $54(38) / 8(5) / 36(22) / 67(41)$ & $44(32) / 7(5) / 25(18) / 60(44)$ & 0.88 \\
\hline Grooming: 0/5 & $82(50) / 82(50)$ & $58(43) / 78(57)$ & 0.20 \\
\hline Bathing: $0 / 5$ & $101(62) / 63(38)$ & $72(53) / 64(47)$ & 0.13 \\
\hline \multicolumn{4}{|c|}{$\begin{array}{l}\text { Table 1: Comparison between pre- and post-resident staffing for acute stroke rehabilitation. } \\
\text { SAH: subarachnoid hemorrhage, NPO: nil per os (nothing by mouth), TF: tube feeding. } \\
\text { Average values were compared using the t-test, and percentage values were analyzed using the } \chi 2 \text { test. } \\
\text { All values are expressed as } n(\%) \text { or mean } \pm \text { standard deviation. }\end{array}$} \\
\hline
\end{tabular}


Citation: Ogushi W, Okabe H, Shomura M, Uematsu H, Nishimura Y, et al. (2021) Effect of Resident Staffing for Acute Stroke Rehabilitation in the Neurosurgery Unit. Int J Nurs Clin Pract 8: 348. doi: https://doi.org/10.15344/2394-4978/2021/348

Page 3 of 5

\begin{tabular}{|c|c|c|}
\hline Variables & Univariate analysis & $\begin{array}{l}\text { Multivariate } \\
\text { analysis }\end{array}$ \\
\hline Sex: Male/ Female & $0.93(0.57-1.53)$ & \\
\hline Age (years) & $1.03(1.01-1.05)$ & \\
\hline $\begin{array}{l}\text { Major diagnosis: SAH/ } \\
\text { cerebral hemorrhage/cerebral } \\
\text { infarction }\end{array}$ & $1.12(0.78-1.63)$ & \\
\hline Hospitalization (days) & $1.06(1.04-1.08)$ & \\
\hline $\begin{array}{l}\text { Resident acute stroke } \\
\text { rehabilitation staffing yes/no }\end{array}$ & $1.72(1.03-2.78)$ & $2.17(1.06-4.35)$ \\
\hline Family care yes/no & $4.76(1.64-14.29)$ & \\
\hline $\begin{array}{l}\text { Number of days required to } \\
\text { start rehabilitation }\end{array}$ & $1.05(0.97-1.14)$ & \\
\hline $\begin{array}{l}\text { Number of days required to } \\
\text { start oral intake }\end{array}$ & $1.08(1.03-1.12)$ & \\
\hline $\begin{array}{l}\text { Number of nursing records } \\
\text { per day }\end{array}$ & $1.50(0.98-2.29)$ & \\
\hline $\begin{array}{l}\text { Number of rehabilitation } \\
\text { records per day }\end{array}$ & $1.76(1.15-2.68)$ & \\
\hline $\begin{array}{l}\text { Physical therapist } \\
\text { intervention yes/no }\end{array}$ & 1.00 (1.00-Infinity) & \\
\hline $\begin{array}{l}\text { Occupational therapist } \\
\text { intervention yes/no }\end{array}$ & $1.49(0.87-2.54)$ & \\
\hline $\begin{array}{l}\text { Speech and swallow therapist } \\
\text { intervention yes/no }\end{array}$ & $3.13(1.82-5.38)$ & \\
\hline $\begin{array}{l}\text { Japan Coma Scale score } \\
\text { at the time of discharge } \\
0 / 1 / 2 / 3 / 10 / 20 / 30 / 100 / 200\end{array}$ & $0.27(0.17-0.41)$ & $0.46(0.27-0.77)$ \\
\hline $\begin{array}{l}\text { Dietary form: } 3 \text { NPO or TF/2 } \\
\text { jelly-like food or less/1 start } \\
\text { meal or more }\end{array}$ & $0.54(0.43-0.68)$ & \\
\hline \multicolumn{3}{|c|}{ Barthel Index scores at the time of discharge } \\
\hline Feeding :0/5/10 & $9.09(4.55-16.67)$ & $16.67(1.03-2.70)$ \\
\hline $\begin{array}{l}\text { Mobility on level surfaces: } \\
0 / 5 / 10 / 15\end{array}$ & $4.35(2.94-6.25)$ & \\
\hline Bowel control: /5/10 & $11.11(5.26-25.00)$ & \\
\hline Bladder control: $0 / 5 / 10$ & $11.11(5.00-25.00)$ & \\
\hline Toilet use: $0 / 5 / 10$ & $11.11(5.88-20.00)$ & \\
\hline Dressing: 0/5/10 & $11.11(6.25-20.00)$ & \\
\hline Stairs: $0 / 5 / 10$ & $9.09(5.56-16.67)$ & \\
\hline $\begin{array}{l}\text { Transfers (bed to chair and } \\
\text { back): } 0 / 5 / 10 / 15\end{array}$ & $8.33(4.55-16.67)$ & $5.88(2.86-12.50)$ \\
\hline Grooming: 0/5 & $33.33(11.11-100.00)$ & \\
\hline Bathing: 0/5 & $33.33(16.67-100.00)$ & \\
\hline \multicolumn{3}{|c|}{$\begin{array}{l}\text { Table 2: Factors associated with home discharge }(\mathrm{n}=301) \text {. } \\
\text { SAH: subarachnoid hemorrhage, NPO: nil per os (nothing by mouth), TF: tube feeding } \\
\text { All results are denoted as odds ratios and } 95 \% \text { confidence intervals. Higher odds ratios } \\
\text { indicate a positive effect on home discharge (earlier discharge). }\end{array}$} \\
\hline
\end{tabular}

\begin{tabular}{|c|c|c|}
\hline Variables & Univariate analysis & $\begin{array}{l}\text { Multivariate } \\
\text { analysis }\end{array}$ \\
\hline Sex: Male/ Female & $0.91(0.58-1.43)$ & \\
\hline Age (years) & $1.06(0.79-1.45)$ & \\
\hline $\begin{array}{l}\text { Major diagnosis: SAH/ } \\
\text { cerebral hemorrhage/ } \\
\text { cerebral infarction }\end{array}$ & $1.56(1.10-2.22)$ & $2.50(1.52-4.17)$ \\
\hline Home discharge yes/no & $7.69(4.17-14.29)$ & $3.23(1.47-7.14)$ \\
\hline $\begin{array}{l}\text { Resident acute stroke } \\
\text { rehabilitation staffing yes/no }\end{array}$ & $1.41(0.88-2.22)$ & $1.75(0.96-3.23)$ \\
\hline Family care yes/no & $0.97(0.51-1.85)$ & \\
\hline $\begin{array}{l}\text { Number of days required to } \\
\text { start rehabilitation }\end{array}$ & $1.08(1.00-1.16)$ & \\
\hline $\begin{array}{l}\text { Number of days required to } \\
\text { start oral intake }\end{array}$ & $1.11(1.07-1.16)$ & \\
\hline $\begin{array}{l}\text { Number of nursing records } \\
\text { per day }\end{array}$ & $1.75(1.23-2.50)$ & $1.72(1.10-2.70)$ \\
\hline $\begin{array}{l}\text { Number of rehabilitation } \\
\text { records per day }\end{array}$ & $1.07(1.38-2.78)$ & $1.59(1.05-2.38)$ \\
\hline $\begin{array}{l}\text { Physical therapist } \\
\text { intervention yes/no }\end{array}$ & $20.00(0.17-20.00)$ & \\
\hline $\begin{array}{l}\text { Occupational therapist } \\
\text { intervention yes/no }\end{array}$ & $0.92(0.56-1.52)$ & \\
\hline $\begin{array}{l}\text { Speech and swallow therapist } \\
\text { intervention yes/no }\end{array}$ & $2.08(1.33-3.33)$ & \\
\hline $\begin{array}{l}\text { Japan Coma Scale score } \\
\text { at the time of discharge } \\
0 / 1 / 2 / 3 / 10 / 20 / 30 / 100 / 200\end{array}$ & $0.85(0.78-0.92)$ & $0.93(0.86-0.99)$ \\
\hline $\begin{array}{l}\text { Dietary form: } 3 \text { NPO or } \\
\text { TF/2 jelly-like food or less/ } 1 \\
\text { start meal or more }\end{array}$ & $0.33(0.23-0.46)$ & \\
\hline \multicolumn{3}{|c|}{ Barthel Index scores at the time of discharge } \\
\hline Feeding: 0/5/10 & $2.70(2.04-3.57)$ & \\
\hline $\begin{array}{l}\text { Mobility on level surfaces: } \\
0 / 5 / 10 / 15\end{array}$ & $2.00(1.67-2.44)$ & \\
\hline Bowel control: 0/5/10 & $2.70(2.04-3.45)$ & \\
\hline Bladder control: $0 / 5 / 10$ & $2.78(2.13-3.70)$ & $1.79(1.20-2.63)$ \\
\hline Toilet use: $0 / 5 / 10$ & $2.94(2.27-4.00)$ & \\
\hline Dressing: 0/5/10 & $2.78(2.13-3.70)$ & \\
\hline Stairs: $0 / 5 / 10$ & $3.03(2.33-4.17)$ & \\
\hline $\begin{array}{l}\text { Transfers (bed to chair and } \\
\text { back): } 0 / 5 / 10 / 15\end{array}$ & $2.08(1.72-2.56)$ & \\
\hline Grooming: 0/5 & $5.56(3.33-9.09)$ & \\
\hline Bathing: $0 / 5$ & $5.26(3.23-9.09)$ & \\
\hline \multicolumn{3}{|c|}{$\begin{array}{l}\text { Table 3: Factors associated with hospitalization ( } \mathrm{n}=301) \text {. } \\
\text { SAH: subarachnoid hemorrhage, NPO: nil per os (nothing by mouth), } \\
\text { TF: tube feeding } \\
\text { All results are denoted as odds ratios and } 95 \% \text { confidence intervals. } \\
\text { Higher odds ratios indicate a positive effect on hospitalization (decreased } \\
\text { duration). }\end{array}$} \\
\hline
\end{tabular}


Citation: Ogushi W, Okabe H, Shomura M, Uematsu H, Nishimura Y, et al. (2021) Effect of Resident Staffing for Acute Stroke Rehabilitation in the Neurosurgery Unit. Int J Nurs Clin Pract 8: 348. doi: https://doi.org/10.15344/2394-4978/2021/348

Page 4 of 5

negatively affected the days of hospitalization. In contrast, all aspects of better BI scores were associated with shorter hospitalization. In the multivariate analysis, we included 10 variables as independent factors, such as resident rehabilitation staffing, major diagnosis, JCS score at discharge, BI scores of feeding, transfer, bladder control, the number of days required to start rehabilitation, the number of nursing and rehabilitation cooperation records, and home discharge. We observed that major diagnosis, home discharge, number of nursing and rehabilitation records, and BI score of bladder control had a significantly positive effect on shorter hospitalization. However the JCS score at discharge had a negative effect on hospitalization. Hence, we detected seven factors independently associated with hospitalization. Further, we could determine the differences in hospitalization pre- and post-resident staffing for acute stroke rehabilitation using the Kaplan-Meier analysis (Figure 1a). However, the multivariate logistic analysis showed that resident staffing did not significantly affect hospitalization. Hospitalization among patients with the three major diagnoses showed significant differences in the Kaplan-Meier analysis (Figure 1b).

\section{Discussion}

We found that resident staffing for acute stroke rehabilitation might contribute to shorter hospitalization, increased cooperation among nursing and rehabilitation therapists, increased home discharge, and improved ADLs and bowel and bladder control; similar findings were reported in a previous study [12]. However, we could only reveal that rehabilitation staffing significantly affected home discharge, and not hospitalization, using the multivariate analysis.

In Kaplan-Meier analysis, resident rehabilitation staffing had a significant effect on the hospitalization period; however, the effect was not significant in multivariate regression analysis. Since there were several hospital transfers, the absence of a significant effect might be attributed to the extension of the hospitalization period owing to insufficient beds in the acute care hospital or extension due to the convenience of the transfer destination facility.

Table 1 shows that bladder and bowel incontinence significantly improved at the time of post-staffing. A previous study revealed that

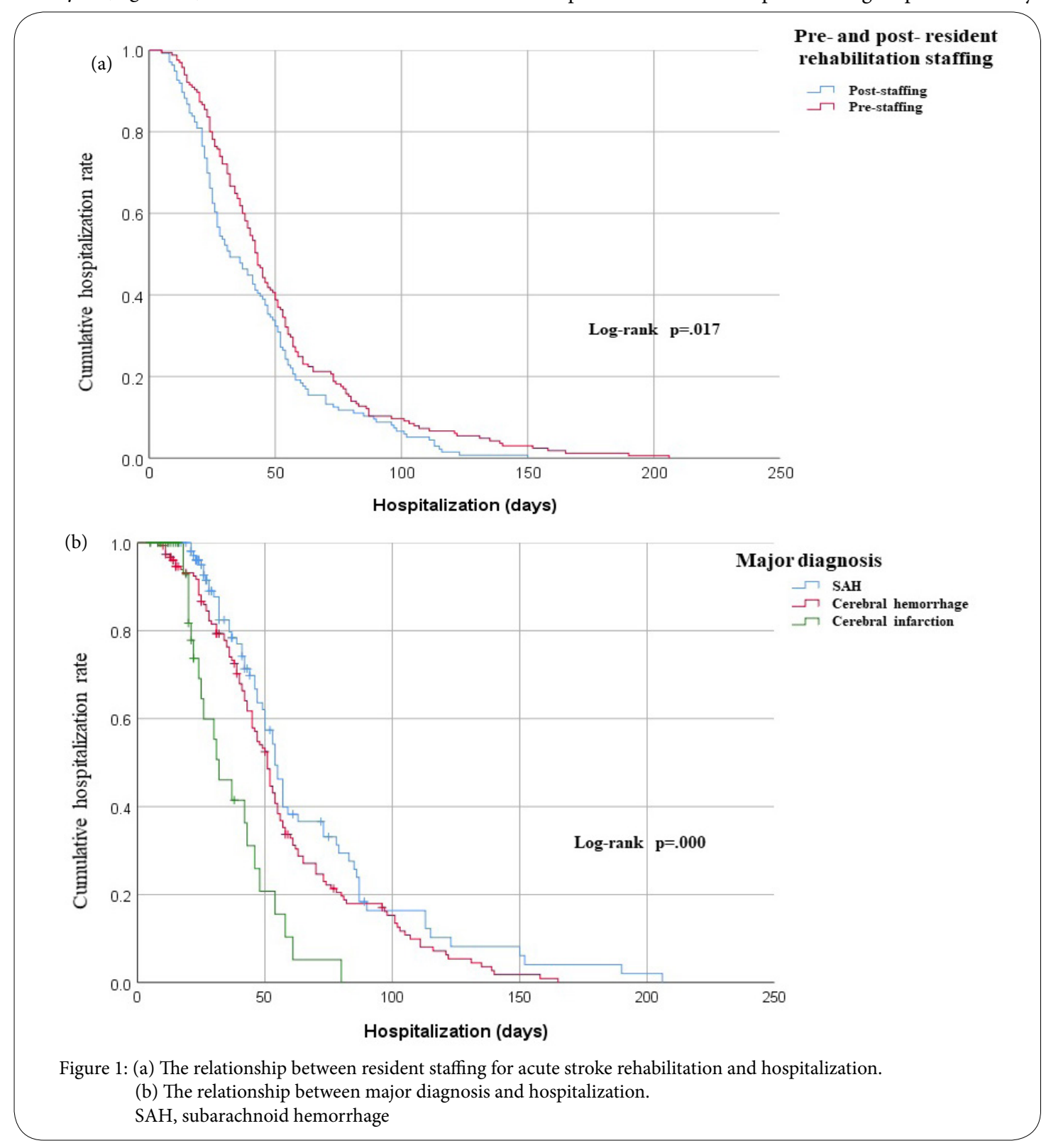


the presence of bladder and bowel incontinence improved postacute stroke rehabilitation. Age and cognitive and leg motor function impairments were related to incontinence [13]. No differences in age, consciousness, and physical impairments were observed between the pre-and post-staffing groups. Hence, in this study, residential staffing might have contributed to the decrease in incontinence owing to the increased opportunity of sharing information about the ADL recovery of patients with stroke and the prompt initiation of ideal support strategies for patients between resident therapists and nurses.

The increase in the number of cooperation records of nursing and rehabilitation staff contributed to increased home discharge and shorter hospitalization. A previous study suggested that the increase in cooperation between rehabilitation staff and nurses is an important factor in shortening the continuity of care in community-based hospitals [12]. By increasing resident rehabilitation staffing, almost all patients in the ward can be adequately attended to. In addition, currently, the rehabilitation staff can incorporate ADLs into the patients' rehabilitation program. Regarding rehabilitation activities, the staff can plan the rehabilitation; however, nurses and therapists can share responsibility for providing prompt rehabilitation in daily practice in the ward, such that nurses can regularly intervene. These are common practices in chronic/post-acute rehabilitation hospitals; however, we believe that the rehabilitation practice in acute care hospitals is innovative and facilitates the speedy recovery of patients. Information can be promptly shared among resident rehabilitation staff in each ward. This can be performed based on the patient's recovery situation by "visible cooperation" and incorporating the rehabilitation protocol into daily life, which might increase the rates of home discharge for stroke patients and improve ADL status at the time of discharge or referral to other institutions.

For home discharge, better feeding and transfers could be positive contributory factors; in contrast, for hospitalization, better bladder control might be a significant contributory factor. In addition, a previous study revealed that evaluation and improvement of ADLs could be an expected factor affecting patient outcomes [14]. Therefore, periodic monitoring of the BI scores by a multidisciplinary team in an acute care setting is important to achieve better clinical outcomes in patients.

We do not have a stroke care unit because university hospitals are expected to fulfill many specialized and advanced roles, such as superacute emergency medical center and comprehensive oncology center, among others. Therefore, it is often difficult to have an independent center dedicated to stroke. This study investigated the significance of having a multidisciplinary stroke center from the perspective of nurses and rehabilitation staff involved in the case of patients with stroke in the general ward. We suggest that resident staffing for acute stroke rehabilitation may contribute to improved outcomes for both the patients and institutions. Further, nurses play important roles in the interdisciplinary team, both as coordinators and as a voice for the patients [15]. We hope that this research provides evidence toward the increase in multidisciplinary independent stroke care units [16].

Our study has a few limitations. First, the findings of the patients were retrospectively observed in a single academic hospital, and the number of cases was relatively small. Specifically, we only observed patients in the neurosurgery ward; therefore, the number of patients with ischemic stroke was very small. Second, while we focused on the confounding variables in the statistical analysis, it was insufficient to prevent all biasing effects. Third, we focused on diseases and examined responsible lesions; however, we did not distinguish between the impaired parts, such as cases wherein the lesions could not be identified, or the parts of the tents or the subs impairments in the statistical analysis. Hence, further prospective studies employing a multidisciplinary approach in acute stroke rehabilitation are required to confirm our study findings. Moreover, it is important to explore the effects of intervention measures, such as virtual reality training, on muscle strength, mood state, and functional status [17].

\section{Conclusion}

Resident staffing for acute stroke rehabilitation wards may contribute to shorter hospitalization duration, increased cooperation between nursing and rehabilitation staff, increased home discharge, and improved ADLs and bowel and bladder control. In addition, its effectiveness may improve the development of a multidisciplinary rehabilitation approach for patients with stroke.

\section{Competing Interests}

The authors declare that they have no competing interests.

\section{Acknowledgments}

We would like to thank all patients who participated in this clinical research. Also, we appreciate all the resident staff for acute stroke rehabilitation and the nursing staff at Tokai University Hospital, Japan. Finally, we are grateful to the referees for their helpful comments.

\section{Author's Contribution}

WO, HO, and MS analyzed the data and wrote the manuscript. $\mathrm{WO}, \mathrm{HU}$, and $\mathrm{YN}$ collected data and gave suggestions regarding the manuscript. HA provided the participants with information and supervised us through the research process.

\section{References}

1. GBD 2016 Stroke Collaborators (2019) Global, regional, and national burden of stroke, 1990-2016: a systematic analysis for the Global Burden of Disease Study 2016. Lancet Neurol 18: 439-458.

2. Feigin VL, Nguyen G, Cercy K, Johnson CO, Alam T, et al. (2018) Global, regional, and country-specific lifetime risks of stroke, 1990 and 2016. N Engl J Med 379: 2429-2437.

3. Takashima N, Arima H, Kita Y, Fujii T, Miyamatsu N, et al. (2017) Incidence, management and short-term outcome of stroke in a general population of 1.4 million Japanese - Shiga Stroke Registry. Circ J 81: 1636-1646.

4. Bray BD, Ayis S, Campbell J, Hoffman A, Roughton M, et al. (2013) Associations between the organisation of stroke services, process of care, and mortality in England: prospective cohort study. BMJ 346: f2827.

5. Norrving B, Barrick J, Davalos A, Dichgans M, Cordonnier C, et al. (2018) Action plan for stroke in Europe 2018-2030. Eur Stroke J 3: 309-336.

6. Winstein CJ, Stein J, Arena R, Bates B, Cherney LR, et al. (2016) Guidelines for adult stroke rehabilitation and recovery: a guideline for healthcare professionals from the American Heart Association/American Stroke Association. Stroke 47: e98-e169.

7. Stroke Unit Trialists' Collaboration (2013) Organised inpatient (stroke unit) care for stroke. Cochrane Database Syst Rev 9: CD000197.

8. Morris S, Ramsay AIG, Boaden RJ, Hunter RM, McKevitt C, et al. (2019) Impact and sustainability of centralising acute stroke services in English metropolitan areas: retrospective analysis of hospital episode statistics and stroke national audit data. BMJ 364: 11. 
Citation: Ogushi W, Okabe H, Shomura M, Uematsu H, Nishimura Y, et al. (2021) Effect of Resident Staffing for Acute Stroke Rehabilitation in the Neurosurgery Unit. Int J Nurs Clin Pract 8: 348. doi: https://doi.org/10.15344/2394-4978/2021/348

9. Bernhardt J, Churilov L, Ellery F, Collier J, Chamberlain J, et al. (2016) Prespecified dose-response analysis for A Very Early Rehabilitation Trial (AVERT). Neurology 86: 2138-2145.

10. Langhorne P. Bernhardt J, Kwakkel G (2011) Stroke rehabilitation. Lancet (London, England) 377: 1693-1702.

11. Hsueh IP, Lin JH, Jeng JS, \& Hsieh CL (2002) Comparison of the psychometric characteristics of the functional independence measure, 5 item Barthe index, and 10 item Barthel index in patients with stroke. J Neurol Neurosurg Psychiatry 73: 188-190.

12. Kumar A, Adhikari D, Karmarkar A, Freburger J, Gozalo P, et al. (2019) Variation in hospital-based rehabilitation services among patients with ischemic stroke in the United States. Phys Ther 99: 494-506.

13. Kovindha A, Wattanapan $P$, Dejpratham $P$, Permsirivanich W, Kuptniratsaiku $\checkmark$ (2009) Prevalence of incontinence in patients after stroke during rehabilitation: a multi-centre study. J Rehabil Med 41: 489-491.

14. Gindin J, Walter-Ginzburg A, Geitzen M, Epstein S, Levi S, et al. (2007) Predictors of rehabilitation outcomes: a comparison of Israeli and Italian geriatric post-acute care (PAC) facilities using the minimum data set (MDS). J Am Med Dir Assoc 8: 233-242.

15. Dreyer P, Angel S, Langhorn L, Pedersen BB, Aadal L (2016) Nursing roles and functions in the acute and subacute rehabilitation of patients with stroke: going all in for the patient. J Neurosci Nurs 48: 108-115.

16. Luconi F, Rochette A, Grad R, Hallé MC, Chin D, et al. (2020) A multifaceted continuing professional development intervention to move stroke rehabilitation guidelines into professional practice: a feasibility study. Top Stroke Rehabil 27: 401-441.

17. Lin RC, Chiang SL, Heitkemper MM, Weng SM, Lin CF, et al. (2020) Effectiveness of early rehabilitation combined with virtual reality training on muscle strength, mood state, and functional status in patients with acute stroke: a randomized controlled trial. Worldviews Evid Based Nurs 17: 158167. 